\title{
Triceps Brachii Muscle Strength and Architectural Adaptations with Resistance Training Exercises at Short or Long Fascicle Length
}

\author{
Angeliki-Nikoletta Stasinaki ${ }^{1}$, Nikolaos Zaras ${ }^{1}$, Spyridon Methenitis ${ }^{1, *(D)}$, \\ Stavroula Tsitkanou ${ }^{1}$ (D), Argyro Krase ${ }^{2}$, Angeliki Kavvoura ${ }^{1}$ and Gerasimos Terzis ${ }^{1}$ \\ 1 Sports Performance Laboratory, School of Physical Education \& Sports Science, \\ National and Kapodistrian University of Athens, Ethnikis Antistassis 41, Daphne, Athens 17237, Greece; \\ agstasin@phed.uoa.gr (A.-N.S.); nikzar@phed.uoa.gr (N.Z.); statsit@phed.uoa.gr (S.T.); \\ akavvoura@phed.uoa.gr (A.K.); gterzis@phed.uoa.gr (G.T.) \\ 2 Department of Physical Education \& Sport Science, University of Thessaly, Karies, Trikala 42100, Greece; \\ argyrokrase@hotmail.com \\ * Correspondence: smetheni@phed.uoa.gr; Tel.: +30-210-7276173; Fax: +30-210-7276028
}

Received: 13 April 2018; Accepted: 16 May 2018; Published: 22 May 2018

\begin{abstract}
The aim of this study was to investigate whether resistance training at short or long triceps brachii fascicle length induces different muscular strength and architectural adaptations. Nine young, novice, female participants, were trained for 6 weeks (two sessions/week) performing 6 sets $\times 6$-RM (repetition maximum) unilateral cable exercises either with push-downs at short fascicle length (S) or overhead extensions with the contralateral arm at long fascicle length (L) of triceps brachii. Before and after training, 1-RM elbow extension and triceps brachii muscle architecture were evaluated. Muscle architecture was analyzed at $50 \%$ and $60 \%$ of the upper-arm length. Two-dimensional longitudinal muscle area of the triceps long head was also analyzed. The results indicated that 1-RM increased $40.1 \pm 21.3 \%$ and $44.5 \pm 20.1 \%(p<0.01)$ after $\mathrm{S}$ and $\mathrm{L}$, respectively. Muscle thickness at $50 \%$ length was increased $10.7 \pm 15.3 \%(p<0.05)$ and $13.7 \pm 9.0 \%(p<0.01)$ after $\mathrm{S}$ and $\mathrm{L}$, while at $60 \%$ it was increased $15.5 \pm 18.8 \%(p<0.05)$ and $19.4 \pm 16.3 \%(p<0.01)$, respectively. Longitudinal muscle area increased similarly after $\mathrm{S}$ and $\mathrm{L}(p<0.01)$. Fascicle angle and length were not altered with training. These results indicate that muscle strength and architecture of elbow extensors adapt similarly during the first six weeks of resistance training at either long or short fascicle length.
\end{abstract}

Keywords: long head of triceps brachii; panoramic ultrasound imaging; fascicle length

\section{Introduction}

Resistance training is popular among training enthusiasts for increasing muscular strength and mass. Exposure to chronic resistance training induces muscle hypertrophy as well as significant health benefits both for female and male participants [1]. However, compared to males, females have lower muscle mass and therefore lower muscle strength [2]. This difference is even more pronounced for the upper body where the difference may be as large as 50\% [2]. This suggests that resistance training for the upper body musculature is important for females.

Different resistance exercises have been proposed for the upper body musculature. Some of these exercises force the protagonist muscles to work at extended lengths while others at short lengths. Nevertheless, little is known about the effectiveness of each one of these different training positions to promote muscle mass and hypertrophy. It has been proposed that resistance exercise at different muscle lengths may force muscles to work at various areas of the length-tension curve [3]. For example, two of the most popular resistance exercises for strengthening the elbow extensors are the cable push-downs 
and the cable overhead extension performed with a pulley. The long head of the triceps brachii, one of the major elbow extensors, originates from the infraglenoid tubercle of the scapula and it is inserted to the proximal end of the olecranon of the ulna and the fascia of the forearm [4]. This suggests that the former of these exercises is performed with the long head of the triceps brachii presumably at a relatively short muscle length, while the latter exercise is performed with the triceps brachii most likely at a longer length. However, it remains unexplored whether one of these exercises is more beneficial for strength and mass development, especially in novice resistance training female participants.

Recent studies aimed to investigate whether training at different muscle lengths of the knee extensors induces different muscle strength and mass adaptations [5-8]. Recently, it has been reported that 8 weeks of isometric knee extension training at long muscle length induced greater strength gains compared to training at short muscle length [5]. However, although muscle thickness was increased similarly between groups, fascicle length was not altered after the two training interventions [5]. Likewise, isometric training at long muscle length resulted in greater increase in concentric muscle strength whereas training at short muscle lengths induced increases only in isometric strength, which was not related to changes in muscle size [6,7]. In another study, dynamic resistance training using machines and free weights at long muscle length was superior to training at short muscle length [8]. These researchers reported that concentric strength, muscle mass, hypertrophy, and fascicle length of vastus lateralis increased after both training conditions, but more increases were observed after training at long muscle length. However, none of these studies examined the fascicle length of contracting muscles in the respective movement range. To our knowledge, no study has examined triceps brachii muscle strength and mass development with resistance training at different muscle lengths as defined by the muscle fascicle length.

The aim of this study was to investigate whether resistance training of elbow extensors at short or long fascicle length of the triceps brachii long head induces different strength, hypertrophy, and architectural adaptations. Based on previous research cited above, it was hypothesized that resistance training at long fascicle length would induce greater increases in muscle strength and thickness compared to resistance training at short fascicle length.

\section{Materials and Methods}

\subsection{Participants}

Ten female first-year physical education students (mean \pm SD; age $19.3 \pm 0.4$ years, height 166.3 $\pm 6.3 \mathrm{~cm}$, body mass $60.1 \pm 6.1 \mathrm{~kg}$, one repetition maximum (1-RM) in bench press $36.2 \pm 4.8 \mathrm{~kg}$ ) with no resistance training experience, participated in the study. All participants had right-arm dominance and they were healthy with no neuromuscular problems. After detailed oral and written description of the procedures, they gave their written consent to participate in the study. One participant did not complete the training program due to personal reasons unrelated to the study. All procedures were approved by School of Physical Education \& Sports Science, National and Kapodistrian University of Athens Ethics Committee (registration number: 1013, 25 May 2017).

\subsection{Experimental Design}

To compare the effectiveness of dynamic resistance training of the elbow extensors with two different resistance exercises that presumably force the triceps long head to work at short (S) and long (L) fascicle length, respectively, young novice females performed strength training for 6 weeks with unilateral cable push-downs (S) and cable overhead extensions with the contralateral arm (L). Fascicle length was determined in a pilot experiment for each one of the two resistance exercises (see description below). This analysis revealed that during $S$ training, the fascicle length of the long head of the triceps brachii was significantly shorter than in L training. Elbow extension 1-RM, muscle thickness, and two-dimensional longitudinal muscle area of the triceps long head, as well as muscle architecture, were evaluated before and after the training period. Five of the participants were randomly assigned 
to perform $S$ training with the dominant arm and $\mathrm{L}$ training with the non-dominant arm. The rest of the participants performed the $S$ training with the non-dominant arm and the $L$ training with the dominant arm. This training model was adopted to minimize inter-participant variability in training adaptations [9]. In addition, cross-education effect (i.e., adaptations in the contralateral arm), seems to be limited when both limbs are trained with different exercises, due to the fact that cross-education occurs only if there is an absence of any contralateral repeatable muscle activity [10]. Moreover, the acute training parameters were the same in the two interventions, except for the fascicle length during training. However, there is no indication that resistance training at different fascicle lengths may induce different cross-education effects.

\subsection{Training}

Before the training period, participants underwent two familiarization sessions separated by 3 days of rest, using the training exercises described below, with various external loads. Training was performed for 6 weeks, with two training sessions per week, every Monday and Thursday. Each training session was initiated with a short warm-up with static stretching for the upper extremity- and shoulder-musculature followed by one set of ten repetitions of standing push-ups against the wall. Then, participants performed 6 sets $\times 6$-RM unilateral $(\sim 85 \%-1 \mathrm{RM}$; until failure) cable push-downs ( $\mathrm{S}$ training) with two minutes rest between sets. Thereafter, participants performed 6 sets $\times 6$-RM unilateral cable overhead extensions (L training) with the contralateral arm with two minutes rest between sets. When a participant was able to perform 8 repetitions in the last set of each exercise, the load was increased in the subsequent session by approximately $5 \%$. Each of these exercises was performed within a range of $80^{\circ}$ of elbow movement (ROM). The cable push-downs started with the elbow at $90^{\circ}$ and ended at $170^{\circ}\left(180^{\circ}\right.$ : full extension). The cable overhead extensions started at $30^{\circ}$ and ended at $110^{\circ}$ of the elbow. This range of movement, as well as the exact movement path, was explained to each participant during the familiarization sessions. To keep the proper technique and ROM for both the L and S training, a custom made plastic cast was used which limited the movement at the preferred ROM. Verbal feedback was provided by one of the researchers during training regarding the desired movement path and range of motion. Participants were also able to monitor their elbow movement via mirrors during training. The number of sets and repetitions performed for each exercise was identical throughout the training period. However, the training load was different between the exercises (higher for the cable push-downs) because of the use of different absolute external loads. After the initial three training sessions, none of the participants complained about muscle soreness.

\subsection{Fascicle Length in Cable Overhead Extension and Cable Push-Down}

To determine the actual length of the fascicles during $\mathrm{L}$ and $\mathrm{S}$ training, fascicle lengths (fLs) were measured at the middle area ( $60 \%$ of upper arm length; Figure 1) of the triceps long head muscle belly in six participants during isometric contractions. Subjects were asked to hold the maximum possible resistance isometrically for $4 \mathrm{~s}$ during unilateral elbow extensions with cable push-downs (S) while the elbow was at $90^{\circ}$ as well as at $170^{\circ}$. Similarly, they were asked to hold the maximum possible external load isometrically during unilateral cable overhead extensions $(\mathrm{L})$ with the elbow of the contralateral arm at $30^{\circ}$ and $110^{\circ}$. During contractions, a panoramic sonographic image was obtained with the method of extended field of view (see details of image capturing and analysis below). Analysis of the images revealed that there was a significant difference for the fascicle length of the triceps brachii long head between $S$ and $L$ both at the starting and finishing position $(p<0.05, n=6)$. Specifically, fascicle length ranged between $44.2 \pm 5.9$ and $51.3 \pm 4.8 \mathrm{~mm}$ for the $S$, and between $60.1 \pm 7.7$ and $66.5 \pm$ $4.8 \mathrm{~mm}$ for the $\mathrm{L}$. 


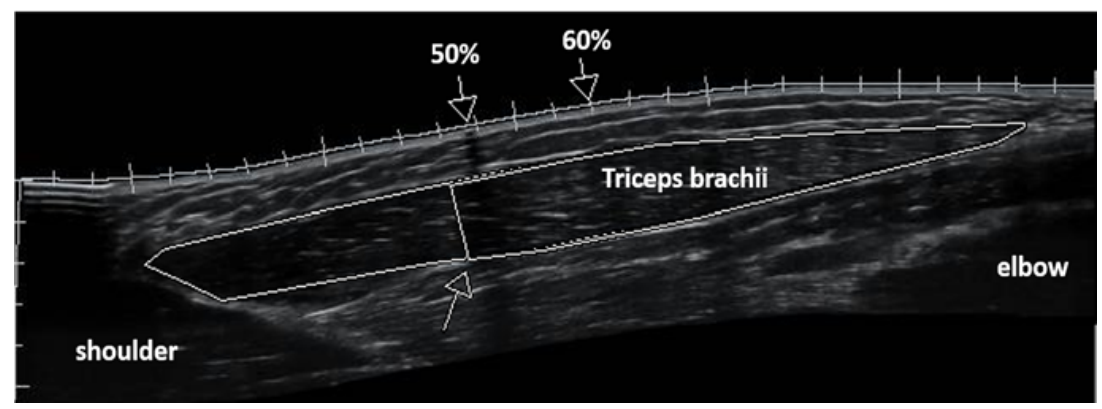

Figure 1. Panoramic sonographic image of triceps brachii muscle. Perimeters of the long head of triceps are shown represented longitudinal muscle area (total, distal, proximal). The arrow on the deep aponeurosis of the long head shows the anatomical point where the middle head joins the long head, which was selected to separate the muscle area as distal (closer to elbow) and proximal (closer to shoulder). Arrows on the superficial aponeurosis show where muscle thickness, pennation angle, and fascicle length were measured at $50 \%$ and $60 \%$ of the upper-arm length.

\subsection{1-RM Elbow Extension}

Before initiation of the study, all participants followed two familiarization sessions for elbow extension 1-RM testing of both upper extremities. The 1-RM assessment was performed according to previous descriptions [11] for each upper extremity using the respective exercise as used during the training period. After reporting to the gym, participants performed a short warm-up (as described previously), then one set of ten repetitions of standing push-ups against the wall and one set of 5 repetitions of submaximal, unilateral elbow extensions. Subsequently, they performed efforts with increasing external loads until they were unable to lift a heavier load (6-7 sets in total) for each one of the two exercises. Two to three minutes of rest were allowed between sets. On a different occasion, the Intraclass Correlation Coefficients (ICC) for elbow extension at S and L was measured in our laboratory (ICCs of $\mathrm{S}=0.91$ and of $\mathrm{L}=0.87, n=12$ ).

\subsection{Muscle Architecture}

All ultrasound measurements before and after training were performed during the morning hours and after subjects remained supine for $20 \mathrm{~min}$ to allow fluid shifts to occur [12]. Pre-training ultrasound images were obtained before the familiarization sessions and maximum strength tests, while the post-training ultrasound images were obtained 5 days after the last training session and 3 days after performing the maximum strength tests, in order to avoid osmotic fluid shifts that may confound architectural or morphological measurements. Panoramic B-mode ultrasound images were obtained with a 38-mm linear probe from the long head of the triceps brachii using the "i-scape" software of the ultrasound device (10.0-MHz, Product model Z5, Shenzhen, Mindray Bio-Medical Electronics Co., Ltd., Shenzhen, China). Initially, participants were placed at a standing position with their arms fully extended to the side of the body. The posterior surfaces of the acromion and the lateral epicondyles of the humerus were marked and used as the total length of the upper arm [13]. The upper arm (starting from acromion) was marked at $50 \%$ and $60 \%$ of the upper-arm length with a permanent pen. Self-adhesive paper was placed on the skin at these two points as a marker (image shadowing). Then, participants laid supine with their arms rested on a laboratory bed at $90^{\circ}$ to their torso, fully extended on elbow joint and supinated. Participants were asked to isometrically contract their triceps, so that the researcher could locate the insertion of the triceps long head using the ultrasound image. Then, the transducer was placed laterally to the arm and oriented in parallel to the muscle fascicles. The transducer's alignment was considered appropriate when several fascicles could be easily outlined without interruption across the image. The fascicle path was drawn on the skin with a pen according to the fascicle path seen from the real-time ultrasound image. To obtain the panoramic image, a continuous single view was taken by moving the probe along the marked line [14]. Images were analyzed (as previously aforementioned) for muscle thickness, fascicle angle, and fascicle 
length at $50 \%$ and $60 \%$ of the upper-arm length [14]. The two-dimensional longitudinal muscle area was calculated in three regions: total, distal, and proximal with image analysis software (Motic Images Plus 2.0, Motic, Hong Kong, China). Longitudinal muscle area was measured using the "polygon" tool of the image analyzing program to analyze the total, proximal, and distal area of the long head of triceps brachii. In each sonographic image, an anatomical point of the deep aponeurosis was identified where the mid triceps head joins the long head. This anatomical point was selected in order to separate the distal (closer to the elbow) and proximal area (closer to shoulder) of the muscle (Figure 1).

Intersession reliability was determined by comparing the analysis of the images obtained by six participants (both arms) on two separate days when skin markings were completely removed. The ICC for the measurement of muscle thickness was 0.984 (95\% Confidence Intervals (CI): 0.951-0.995, $p=0.001)$, ICC for fascicle angle was 0.858 (95\% CI: 0.626-0.952, $p=0.001)$, and for fascicle length it was 0.794 (95\% CI: $0.483-0.928, p=0.001)$. The ICC for the measurement of longitudinal muscle area was 0.963 (95\% CI: $0.887-0.988), p=0.001$.

\subsection{Statistical Analysis}

A post hoc power analysis, was performed according to the study design, the number of the participants, and the lower partial eta Squared of the significant contrasts or of the Pearson's $r$ correlations coefficient that were found, which reveal an actual power of 0.889 for the results of the present study [15]. Accordingly, the power for the correlation coefficients ranged between 0.817 and 0.900 .

All data reports are given as mean \pm SD. A series of one-way analyses of variance (ANOVA) were performed for all baseline data trials to identify any significant differences between training conditions. As expected, a significant difference was found between the $S$ and the $\mathrm{L}$ arms for 1-RM at the initiation of the training period. Therefore, repeated measures analysis of covariance (ANCOVA; with 1-RM pre-test values as covariance) was performed to evaluate differences in 1-RM between $\mathrm{S}$ and $\mathrm{L}$, whereas for the rest of the variables separate analyses of variance with repeated measures were performed. Post-hoc Bonferroni analysis was used to examine pairwise differences whenever a significant $F$-value was obtained. Paired-sample $t$-tests and independent-sample $t$-tests were performed to evaluate training-related changes within groups and between training conditions, respectively. Partial eta squared was also performed; according to Richardson [16], partial eta squared can be used as an indicator of effect size, and it can be classified as small (0.01 to 0.059$)$, moderate (0.06 to 0.137), and large $(\geq 0.138)$. Pearson's (r) product-moment correlation coefficients were computed to explore the relationships between variables. The interpretation of the observed correlations was performed according to Hopkins' ranking: correlations coefficients between $0.3-0.5$ were considered moderate, between $0.51-0.70$ large, between $0.71-0.90$ very large, and $>0.91$ almost perfect [17]. The significance level was set at $p<0.05$. ICCs with $95 \%$ CI (two-way random effects with absolute agreement) were calculated for muscle architecture and longitudinal muscle area. All statistical analyses were performed using SPSS version 21.0 software (SPSS Inc., Chicago, IL, USA).

\section{Results}

Elbow extension 1-RM increased significantly by $40.1 \pm 21.3 \%$ (from $14.86 \pm 2.2 \mathrm{~kg}$ to $20.83 \pm$ $4.8 \mathrm{~kg}, p=0.001$ ) and $44.5 \pm 20.1 \%$ (from $8.56 \pm 2.7 \mathrm{~kg}$ to $12.08 \pm 3.0 \mathrm{~kg}, p=0.000$ ) after S and L training, respectively, while ANCOVA revealed no difference for these changes between groups $(p=0.640$, $\left.\eta^{2}=0.015\right)$.

Results for muscle architecture are presented at Table 1. Muscle thickness at 50\% (MT50\%) and $60 \%$ (MT60\%) of the upper arm length increased significantly, while fascicle length (fL50\%, fL60\%) and fascicle angle (Angle 50\%, Angle $60 \%$ ) were not altered significantly either after S or L training, respectively. There were no differences between groups for any of the muscle architecture variables at $50 \%$ or $60 \%$ of the upper-arm length. Analysis of the two-dimensional longitudinal muscle area revealed a significant increase in total and distal area, while proximal area was not altered significantly after $\mathrm{S}$ and $\mathrm{L}$ training, respectively (Table 1 ). There were no differences between groups for the longitudinal muscle area (total, distal, or proximal, Table 1). 
Table 1. Triceps brachii long head architecture characteristics and longitudinal area (means \pm SD) before and after 6 weeks of resistance training at short (S) and long (L) fascicle length in nine novice physical education female students. $p$ values, independent $t$-test values, and eta ${ }^{2}$ for differences between training conditions are presented.

\begin{tabular}{|c|c|c|c|c|c|}
\hline Parameter & $\begin{array}{c}\text { Time Points/ } \\
\text { Percentage Changes }\end{array}$ & $\begin{array}{l}\text { Short Fascicle Length } \\
\text { Training Group }\end{array}$ & $\begin{array}{l}\text { Long Fascicle Length } \\
\text { Training Group }\end{array}$ & $\begin{array}{c}p \text { Values for the Comparisons } \\
\text { between the Groups }\end{array}$ & $\eta^{2}$ \\
\hline MT50\% (cm) & $\begin{array}{c}\text { Before } \\
\text { After } \\
\% \text { change }\end{array}$ & $\begin{array}{c}1.35 \pm 0.26 \\
1.47 \pm 0.21 \text { * } \\
10.7 \pm 15.3\end{array}$ & $\begin{array}{c}1.29 \pm 0.20 \\
1.46 \pm 0.2{ }^{\S} \\
13.7 \pm 9.0\end{array}$ & $\begin{array}{l}0.448 \\
0.618\end{array}$ & 0.036 \\
\hline $\mathrm{fL50} \%(\mathrm{~cm})$ & $\begin{array}{c}\text { Before } \\
\text { After } \\
\% \text { change }\end{array}$ & $\begin{array}{c}7.95 \pm 1.43 \\
8.56 \pm 1.50 \\
9.0 \pm 16.8\end{array}$ & $\begin{array}{c}8.67 \pm 1.36 \\
8.72 \pm 1.60 \\
1.3 \pm 15.2\end{array}$ & $\begin{array}{l}0.374 \\
0.323\end{array}$ & 0.050 \\
\hline Angle 50\% (degrees) & $\begin{array}{c}\text { Before } \\
\text { After } \\
\% \text { change }\end{array}$ & $\begin{array}{c}11.78 \pm 2.59 \\
11.33 \pm 2.12 \\
-1.2 \pm 18.8\end{array}$ & $\begin{array}{c}10.89 \pm 2.26 \\
11.78 \pm 2.11 \\
10.3 \pm 21.2\end{array}$ & $\begin{array}{l}0.263 \\
0.241\end{array}$ & 0.078 \\
\hline MT60\% (cm) & $\begin{array}{c}\text { Before } \\
\text { After } \\
\% \text { change }\end{array}$ & $\begin{array}{c}1.23 \pm 0.25 \\
1.40 \pm 0.25 * \\
15.5 \pm 18.8\end{array}$ & $\begin{array}{c}1.22 \pm 0.21 \\
1.43 \pm 0.19 \S \\
19.4 \pm 16.3\end{array}$ & $\begin{array}{l}0.565 \\
0.641\end{array}$ & 0.021 \\
\hline $\mathrm{fL} 60 \%(\mathrm{~cm})$ & $\begin{array}{c}\text { Before } \\
\text { After } \\
\% \text { change }\end{array}$ & $\begin{array}{c}9.68 \pm 2.60 \\
9.85 \pm 1.98 \\
6.4 \pm 29.4\end{array}$ & $\begin{array}{l}9.46 \pm 1.71 \\
9.28 \pm 2.13 \\
-1.5 \pm 16.3\end{array}$ & $\begin{array}{l}0.737 \\
0.491\end{array}$ & 0.007 \\
\hline Angle60\% (degrees) & $\begin{array}{c}\text { Before } \\
\text { After } \\
\% \text { change }\end{array}$ & $\begin{array}{c}11.33 \pm 2.45 \\
11.00 \pm 2.12 \\
0.3 \pm 25.6\end{array}$ & $\begin{array}{c}11.22 \pm 1.64 \\
12.00 \pm 2.06 \\
7.2 \pm 13.5\end{array}$ & $\begin{array}{l}0.359 \\
0.485\end{array}$ & 0.053 \\
\hline Area Total $\left(\mathrm{cm}^{2}\right)$ & $\begin{array}{c}\text { Before } \\
\text { After } \\
\% \text { change }\end{array}$ & $\begin{array}{c}16.77 \pm 3.71 \\
19.24 \pm 4.53 * \\
15.3 \pm 16.4\end{array}$ & $\begin{array}{c}16.56 \pm 3.82 \\
18.92 \pm 3.52 \S \\
16.1 \pm 14.1\end{array}$ & $\begin{array}{l}0.917 \\
0.912\end{array}$ & 0.001 \\
\hline Area Distal $\left(\mathrm{cm}^{2}\right)$ & $\begin{array}{c}\text { Before } \\
\text { After } \\
\% \text { change }\end{array}$ & $\begin{array}{c}10.76 \pm 2.00 \\
12.59 \pm 3.39 * \\
16.7 \pm 20.3\end{array}$ & $\begin{array}{c}10.43 \pm 2.54 \\
12.65 \pm 2.35 \S \\
24.9 \pm 25.3\end{array}$ & $\begin{array}{l}0.706 \\
0.460\end{array}$ & 0.009 \\
\hline Area Proximal $\left(\mathrm{cm}^{2}\right)$ & $\begin{array}{c}\text { Before } \\
\text { After } \\
\% \text { change }\end{array}$ & $\begin{array}{l}5.93 \pm 1.98 \\
6.65 \pm 2.28 \\
13.5 \pm 27.8\end{array}$ & $\begin{array}{l}6.34 \pm 1.62 \\
6.27 \pm 2.04 \\
-0.1 \pm 23.0\end{array}$ & $\begin{array}{l}0.260 \\
0.274\end{array}$ & 0.079 \\
\hline
\end{tabular}

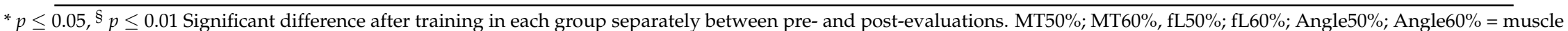
thickness, fascicle length, and pennation angle measured at $50 \%$ and $60 \%$ of upper arm length, respectively. 
Significant correlations were revealed between the percent change of 1-RM and percent change of fL50\% $(r=-0.723, p=0.006)$ and percent change of Angle60\% $(r=0.827, p=0.028)$ only after L training (Figure 2). 1-RM significantly correlated with MT50\%, MT60\%, and longitudinal muscle area at post-training period ( $r=0.706-0.866, p<0.05$, Table 2$)$. No significant correlations were found between the initial 1-RM and MT50\%, MT60\%, and muscle area before training for the S group $(p>0.05)$, as well as for the MT60\% for the L group ( $p>0.05)$. Finally, in both groups, the 1-RM after the training was not correlated with distal muscle area $(p>0.05)$.
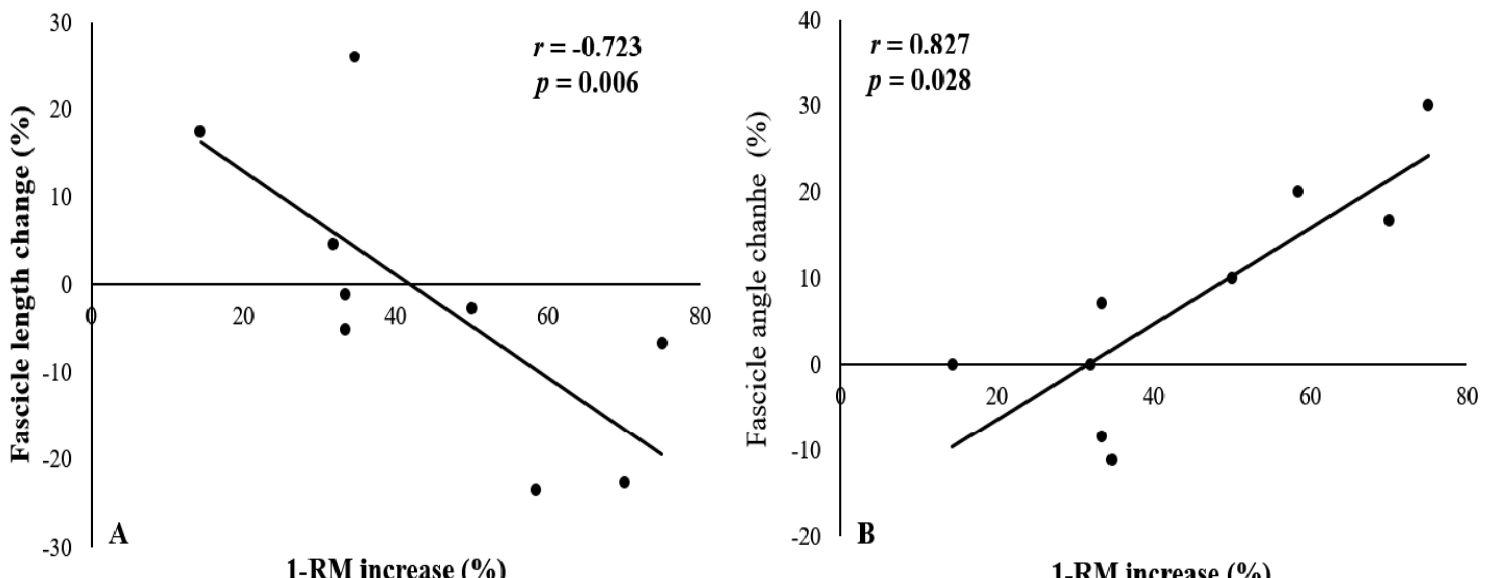

1-RM increase (\%)

Figure 2. Correlation between the percent change in elbow extension 1-RM and the percent change in fascicle length (A), and fascicle angle (B) of the long head of the triceps brachii after 6 weeks of resistance training at long fascicle length in nine novice female physical education students. RM: repetition maximum.

Table 2. Correlation coefficients between elbow extension 1-RM and triceps brachii long head muscle thickness and two-dimensional longitudinal muscle area, before and after the training period.

\begin{tabular}{|c|c|c|c|c|c|}
\hline \multirow{3}{*}{$\begin{array}{c}\text { SHORT } \\
\text { 1-RM before }\end{array}$} & \multicolumn{2}{|c|}{$\begin{array}{l}\text { Triceps Brachii Long Head Muscle Thickness at } \\
50 \% \text { or } 60 \% \text { of Upper-Arm Length before Training }\end{array}$} & \multicolumn{3}{|c|}{ Muscle Area before Training } \\
\hline & $50 \%$ & $60 \%$ & Total & Distal & Proximal \\
\hline & 0.517 & 0.528 & 0.426 & 0.413 & 0.460 \\
\hline & \multicolumn{2}{|c|}{$\begin{array}{l}\text { Triceps Brachii Long Head Muscle Thickness at } \\
50 \% \text { or } 60 \% \text { of Upper-Arm Length after Training }\end{array}$} & \multicolumn{3}{|c|}{ Muscle Area after Training } \\
\hline \multirow[b]{2}{*}{ 1-RM after } & $50 \%$ & $60 \%$ & Total & Distal & Proximal \\
\hline & $0.706^{*}$ & $0.831^{\S}$ & $0.804^{\S}$ & 0.575 & $0.742 *$ \\
\hline LONG & \multicolumn{2}{|c|}{$\begin{array}{l}\text { Triceps Brachii Long Head Muscle Thickness at } \\
50 \% \text { or } 60 \% \text { of Upper-Arm Length before Training }\end{array}$} & \multicolumn{3}{|c|}{ Muscle Area before Training } \\
\hline \multirow{3}{*}{ 1-RM before } & $50 \%$ & $60 \%$ & Total & Distal & $\begin{array}{c}\text { Proximal } \\
0864 \S\end{array}$ \\
\hline & $0.748^{*}$ & 0.610 & $0.866^{8}$ & $0.71 b^{*}$ & $0.864^{8}$ \\
\hline & \multicolumn{2}{|c|}{$\begin{array}{l}\text { Triceps Brachii Long Head Muscle Thickness at } \\
50 \% \text { or } 60 \% \text { of Upper-Arm Length after Training }\end{array}$} & \multicolumn{3}{|c|}{ Muscle Area after Training } \\
\hline & $50 \%$ & $60 \%$ & Total & Distal & Proximal \\
\hline 1-RM after & $0.804^{8}$ & 0.779 * & $0.756^{*}$ & 0.586 & $0.728^{*}$ \\
\hline
\end{tabular}

\section{Discussion}

The main finding of the present study was that elbow extension strength using either the cable push-downs or the cable overhead extensions (i.e., at short or long fascicle length training, respectively) was similarly increased after 6 weeks of resistance training in female novice participants. The former exercise is performed at shorter fascicle length compared with the latter exercise, as estimated in 
the present study. This suggests that during the first weeks of resistance training when muscle strength development is rapid, the fascicle length during exercise has a relatively low effect on strength increments. Interestingly, triceps brachii long head muscle thickness as well as longitudinal muscle area were similarly increased with both exercises. This suggests that triceps brachii long head is similarly recruited with both exercises. As expected, the increase in elbow extensors' strength was much higher (40-44\%) than the increase in muscle thickness (10-15\%) and longitudinal area (14-25\%). This suggests the presence of neural adaptations, which may be explained by the novice nature of the participants [18-20]. Longer training periods might have resulted in a greater involvement of muscle hypertrophy in the strength increases observed, which might have also induced greater triceps brachii architectural adaptations. However, muscle thickness was similarly increased after the two training conditions, which is in agreement with a recent study in the lower extremities [5]. This may suggest a similar recruitment pattern for the long head of triceps brachii between the two exercises used in this study, despite the different ranges of fascicle lengths during training.

In a recent study [8], it was found that training at long fascicle length induced greater increases in strength, distal muscle cross sectional area, and fascicle length of vastus lateralis accompanied by increases in Insulin-Like Growth Factor 1 (IGF-1), as compared to training at short fascicle length. It is worth noting that the range of fascicle length used during training was not measured in that previous study [8]. Nevertheless, the apparent discrepancy with the current results might be related to the longer training duration and/or the training experience of the participants. It may be speculated that architectural adaptations might have followed the initial 12 training sessions in the current study. Indeed, the small, however non-significant difference in strength increase ( $44 \%$ vs. $40 \%$ ), muscle thickness (15\% vs. $10 \%)$, and hypertrophy (16-25\% vs. $14-17 \%$ ) increase in favor of the cable overhead extensions exercise might be an indication for such adaptations, particularly if training was to be continued for a longer duration. Also, in the study of McMahon et al. (2014), training was performed for 8 weeks, with three sessions per week, and 4 sets of $8-10$ reps for $4-5$ exercises per session in moderately trained males, which also suggests a great variance in the training load in favor of the earlier study [8]. Although application of a large training load would be inappropriate in the current study due to the novice nature of the participants, it may not be excluded that the lack of difference in fascicle length increase between the current study and the study of McMahon et al. (2014) may be due to the differences in the training volume applied. Moreover, it should be mentioned that the lower extremities are used more often in everyday life compared to the elbow extensors, which might imply an elevated initial baseline for vastus lateralis muscle in the study by McMahon et al. (2014), as compared to the less trained triceps brachii in novice females.

While strength training induced significant increases in strength, the muscle architecture of the long head of the triceps did not change significantly, which is in accordance with a previous study [21]. Interestingly, in this previous study, there was a uniform architectural adaptation at $50 \%$ and $60 \%$ of the triceps brachii length, as found here. Before the initiation of the study it was hypothesized that training at long muscle length would induce increases in muscle fascicle length, since such a result has been reported before [8]. However, it seems that the short training duration together with the novice nature of the participants did not allow for such an adaptation to occur. Similarly, a previous study reported that 5 weeks of resistance training were inadequate to alter muscle architecture of the quadriceps, even if strength was increased [22]. The results of the present study revealed that the fascicle length of the triceps long head was not altered after either S or L training, which is in agreement with results reported from Alegre et al. (2014) [5]. The current results suggest that performing either the cable push-downs (short fascicle length) or the cable overhead extensions (long fascicle length) may not significantly alter the fascicle length of the triceps brachii long head, at least during the first 6 weeks of training, in novice female participants.

Triceps brachii is an important contributor to several sports such as the track and field throws [23], baseball, and rugby, and it determines most of the muscle volume of the upper arm [24]. There are a lot of resistance training exercises that are used to develop its mass and strength, however, 
little is known about the effectiveness of these exercises. The present study investigated for the first time the resistance training adaptations using two different exercises where the long head of the triceps brachii is working at different fascicle lengths. However, there are certain limitations in the current study. The first limitation was the different training loads between the two experimental groups. However, this was due to the nature of these exercises. In addition, as mentioned above, the large increase in muscle strength combined with a much lower increase in muscle thickness suggest strong neural adaptations after training either with cable push-downs or cable overhead extensions. Unfortunately, it was not possible to evaluate the electromyographic signals from triceps brachii in this study, which might have provided a better insight into the training adaptations since such result has been that occurred. Likewise, a longer training period might have increased the muscular component of the training adaptations, which would probably have provided a clearer illustration of the triceps brachii architectural changes. Another possible limitation of this study was the lack of analysis of the architectural characteristics of the other two heads of the triceps brachii. Given the anatomical points of origin and insertion of these triceps brachii heads, it may be assumed that their fascicle lengths would behave similarly as those of the long head during cable push-downs and cable overhead extensions. However, this question should be addressed in a future study.

The results of the present study are of practical importance. The results of this study suggest that during the first weeks of resistance training both cable push-downs and cable overhead extensions are equally effective at inducing elbow extension muscle strength in novice young females. This increase in strength seems to be partly due to increases in muscle mass of the triceps long head while neural factors may contribute significantly. This type of resistance training seems not to affect the muscle architecture (fascicle angle and length) of the triceps long head. Resistance training for six weeks in novice participants does not seem to be an adequate stimulus for fascicle length increase. In addition, it seems that when young, novice female participants are involved, just two resistance training sessions per week with sets of 6-RM provide an adequate stimulus for elbow extension muscle strength increase and hypertrophy.

\section{Conclusions}

In conclusion, muscle strength of elbow extensors increased similarly with cable push-downs and cable overhead extensions during the first six weeks of resistance training in novice female participants. Muscle thickness also increased similarly. These two different exercises force the muscle to work in short and long fascicle lengths, respectively. This suggests that during the first weeks of resistance training, when triceps brachii muscle strength development is rapid, the fascicle length during exercise has a relatively low effect on strength increments and muscle architecture.

Author Contributions: A.-N.S., S.M., and G.T. conceived and designed the experiments; A.-N.S., N.Z., S.T., Ar.K., and An.K. performed the experiments and analyzed the data; A.-N.S., S.M., and G.T. contributed reagents/materials/analysis tools; A.-N.S., S.M., and G.T. wrote the paper.

Acknowledgments: We wish to express our gratitude to the subjects of the present study. All experimental procedures used comply with local governmental laws for human subjects. No grant support was received for this study.

Conflicts of Interest: The authors declare no conflict of interest

\section{References}

1. Pedersen, B.K.; Saltin, B. Exercise as medicine-evidence for prescribing exercise as therapy in 26 different chronic diseases. Scand. J. Med. Sci. Sports 2015, 25, 1-72. [CrossRef] [PubMed]

2. Fleck, J.; Kraemer, W. Designing Resistance Training Programs, 3rd ed.; Human Kinetics: Champaing, IL, USA, 2009.

3. Vogt, M.; Hoppeler, H. Eccentric exercise: Mechanisms and effects when used as training regime or training adjunct. J. Appl. Physiol. 2014, 116, 1446-1454. [CrossRef] [PubMed]

4. Agur, A.; Dalley, A. Grant's Atlas of Anatomy; Lippincott Williams \& Wilkins: Philadelphia, PA, USA, 2009. 
5. Alegre, L.M.; Ferri-Morales, A.; Rodriguez-Casares, R.; Aguado, X. Effects of isometric training on the knee extensor moment-angle relationship and vastus lateralis muscle architecture. Eur. J. Appl. Physiol. 2014, 114, 2437-2446. [CrossRef] [PubMed]

6. Noorkõiv, M.; Nosaka, K.; Blazevich, A.J. Neuromuscular adaptations associated with knee joint angle-specific force change. Med. Sci. Sports Exerc. 2014, 46, 1525-1537. [CrossRef] [PubMed]

7. Noorkõiv, M.; Nosaka, K.; Blazevich, A. Effects of isometric quadriceps strength training at different muscle lengths on dynamic torque production. J. Sports Sci. 2015, 33, 1952-1961. [CrossRef] [PubMed]

8. McMahon, G.; Morse, C.; Burden, A.; Winwood, K.; Onambélé, G.L. Muscular adaptations and insulin-like growth factor-1 responses to resistance training are stretch-mediated. Muscle Nerve 2014, 49, 108-119. [CrossRef] [PubMed]

9. MacInnis, M.; McGlory, C.; Gibala, M.; Phillips, S. Investigating human skeletal muscle physiology with unilateral exercise models: When one limb is more powerful than two. Appl. Physiol. Nutr. Metab. 2017, 42, 563-570. [CrossRef] [PubMed]

10. Lasevicius, T.; Ugrinowitsch, C.; Schoenfeld, B.; Roschel, H.; Tavares, L.D.; De Souza, E.O.; Laurentino, G.; Tricoli, V. Effects of different intensities of resistance training with equated volume load on muscle strength and hypertrophy. Eur. J. Sport Sci. 2018, 22, 1-9. [CrossRef] [PubMed]

11. Baechle, T.R.; Earle, R.W.; Wathen, D. Resistance training. In Essentials of Strength Training and Conditioning, 2nd ed.; Baechle, T.R., Earle, R.W., Eds.; Human Kinetics: Champaign, IL, USA, 2000; pp. 395-425.

12. Reeves, N.; Maganaris, C.; Narici, M. Ultrasonographic assessment of human skeletal muscle size. Eur. J. Appl. Physiol. 2004, 91, 116-118. [CrossRef] [PubMed]

13. Miyatani, M.; Kanehisa, H.; Ito, M.; Kawakami, Y.; Fukunaga, T. The accuracy of volume estimates using ultrasound muscle thickness measurements in different muscle groups. Eur. J. Appl. Physiol. 2004, 91, 264-272. [PubMed]

14. Noorkoiv, M.; Stavnsbo, A.; Aagaard, P.; Blazevich, A. In vivo assessment of muscle fascicle length by extended field-of-view ultrasonography. J. Appl. Physiol. 2010, 109, 1974-1979. [CrossRef] [PubMed]

15. Faul, F.; Erdfelder, E.; Lang, A.G.; Buchner, A. G* power 3: A flexible statistical power analysis program for the social, behavioral, and biomedical sciences. Behav. Res. Methods 2007, 39, 175-191. [CrossRef] [PubMed]

16. Richardson, J.T. Eta squared and partial eta squared as measures of effect size in educational research. Educ. Res. Rev. 2011, 6, 135-147. [CrossRef]

17. Hopkins, W.G. Measures of reliability in sports medicine and science. Sports Med. 2000, 30, 1-15. [CrossRef] [PubMed]

18. Narici, M.V.; Roi, G.S.; Landoni, L.; Minetti, A.E.; Cerretelli, P. Changes in force, cross-sectional area and neural activation during strength training and detraining of the human quadriceps. Eur. J. Appl. Physiol. 1989, 59, 310-319. [CrossRef]

19. Aagaard, P.; Simonsen, E.B.; Andersen, J.L.; Magnusson, P.; Dyhre-Poulsen, P. Neural adaptation to resistance training: Changes in evoked V-wave and H-reflex responses. J. Appl. Physiol. 2002, 92, 2309-2318. [CrossRef] [PubMed]

20. Sale, D.G. Neural adaptation to resistance training. Med. Sci. Sports Exerc. 1988, 20, S135-S145. [CrossRef] [PubMed]

21. Matta, T.; Simão, R.; de Salles, B.F.; Spineti, J.; Oliveira, L.F. Strength training's chronic effects on muscle architecture parameters of different arm sites. J. Strength Cond. Res. 2011, 25, 1711-1717. [CrossRef] [PubMed]

22. Blazevich, A.; Gill, N.; Bronks, R.; Newton, R. Training-specific muscle architecture adaptation after 5-wk training in athletes. Med. Sci. Sports Exerc. 2003, 35, 2013-2022. [CrossRef] [PubMed]

23. Terzis, G.; Karampatsos, G.; Georgiadis, G. Neuromuscular control and performance in shot-put athletes. J. Sports Med. Phys. Fit. 2007, 47, 284-290.

24. Ogasawara, R.; Thiebaud, R.; Loenneke, J.; Loftin, M.; Abe, T. Time course for arm and chest muscle thickness changes following bench press training. Interv. Med. Appl. Sci. 2012, 4, 217-220. [CrossRef] [PubMed]

(C) 2018 by the authors. Licensee MDPI, Basel, Switzerland. This article is an open access article distributed under the terms and conditions of the Creative Commons Attribution (CC BY) license (http:/ / creativecommons.org/licenses/by/4.0/). 